UDC 34.01

LBC 67.0

\title{
THE IMPLEMENTATION OF LAW-MAKING FUNCTIONS AS A MANIFESTATION OF THE ORGANIZATIONAL CULTURE OF A LEGAL PROCESS ${ }^{1}$
}

\author{
Vasily V. Trofimov \\ Tambov State University, Tambov, Russian Federation \\ Vladimir Yu. Samorodov \\ Tambov State University, Tambov, Russian Federation
}

\begin{abstract}
Introduction: the article deals with the legal concept of creativity as a planned and conscious way of lawmaking process, however, due to the social nature of law. The law-making activity is represented by a particular system, which involves the implementation of the necessary functions aimed at solving tasks of improving the modern legislation. The authors 'strivings are aimed at detecting the problems in the implementation of the lawmaking functions in the context of the organizational culture of law-making process. In this context, the purpose for this research work is to identify the above-mentioned problems, study them and offer reasoned cultural requirements to law-making process. By applying the general scientific methods (dialectic, analysis, synthesis, systemology, classification) and specially scientific (formal-legal, comparative law, interpretive, juridical linguistic, legal modeling) methods the authors attempted to reveal the subject of the article and get some new knowledge - heuristic results on the matter researched, including those indicating the compliance of law-making process with the certain specific cultural requirements. Results: the article presents a number of cultural and organizational requirements with the experience justifying the need of imposing them on law-making process. According to the authors, these requirements are intended to minimize the problems of implementing the law-making functions and make the process more efficient and its products (rules of law) more balanced, in the public interest, and socialized - perceived by the society. The relationship between the culture of the society and legal work are focused on. The scope of the results is a modern law-making process aimed at establishing the effective rules of law. Conclusions: law making is very important state-social activities; the results of its implementation determine the state of law and order in the society, and stable development of the state. During this process various functions are implemented. For them to be implemented effectively, the legal process itself of systematically-rational law-making should be at a high cultural level and meet a specific set of cultural requirements. In this regard, it is necessary to strive to improve the organizational culture of law-making process in all its phases and stages.

Key words: law, society, legislation, law-making, law-making functions, culture of law-making, judicial process, law-making technique.
\end{abstract}

\section{РЕАЛИЗАЦИЯ ПРАВОТВОРЧЕСКИХ ФУНКЦИЙ КАК ПРОЯВЛЕНИЕ КУЛЬТУРЫ ОРГАНИЗАЦИИ ЮРИДИЧЕСКОГО ПРОЦЕССА ${ }^{1}$}

\author{
Василий Владиславович Трофимов
}

Тамбовский государственный университет им. Г.Р. Державина, г. Тамбов, Российская Федерация

\section{Владимир Юрьевич Самородов}

Тамбовский государственный университет им. Г.Р. Державина, г. Тамбов, Российская Федерация

Введение: в статье рассматривается понятие правового творчества как планомерно-сознательного способа правообразования, вместе с тем обусловленного социальной природой права. Правотворческая 
деятельность представляется определенной системой, которая предполагает осуществление необходимых функций, направленных на решение задач совершенствования современного законодательства. Усилия авторов нацелены на обнаружение проблем реализации правотворческих функций в контексте культуры организации правотворческого процесса. В этой связи целью данной научной работы является раскрытие вышеуказанных проблем, их изучение и предложение аргументированных культурных требований, предъявляемых к правотворческому процессу. С помощью общенаучных (диалектика, анализ, синтез, системология, классификация) и частнонаучных (формально-юридический, сравнительно-правовой, интерпретационный, юрислингвистический, правового моделирования) методов авторы попытались наиболее полно раскрыть предмет данной статьи и получить некоторые новые знания - например, эвристические результаты по изучаемому вопросу, в том числе указывающие на необходимость соответствия правотворческого процесса определенным характерным культурным требованиям. Результаты: в статье представлен ряд культурноорганизационных требований с опытом обоснования необходимости их предъявления к правотворческому процессу. По мнению авторов, данные требования призваны минимизировать проблемы реализации функций правотворчества и сделать этот процесс наиболее эффективным, а его продукты (нормы права) - более сбалансированными, отвечающими общественным интересам и социализируемыми (воспринимаемыми обществом). Акцентируется внимание на взаимосвязь культуры социума и правового творчества. Областью применения результатов является современный правотворческий процесс, направленный на создание эффективных норм права. Выводы: правотворчество - это крайне значимая государственно-социальная деятельность, итоги его осуществления предопределяют состояние законности и правопорядка в обществе, стабильность развития государства. В ходе этого процесса реализуются различные функции. Для того, чтобы они реализовывались эффективно, сам юридический процесс планомерно-рационального правосозидания должен осуществляться на высоком культурном уровне и отвечать определенному набору культурных требований. В этой связи необходимо стремиться к повышению культуры организации правотворческого процесса на всех его этапах и стадиях.

Ключевые слова: право, общество, правообразование, правотворчество, правотворческие функции, культура правотворчества, юридический процесс, техника правотворчества.

\section{Введение}

Общетеоретические вопросы правотворчества - это вопросы, связанные с пониманием того, как и кем формируется (творится) право, каким объективным законам подчиняется данный процесс, каким правокультурным требованиям он должен соответствовать, чтобы приводить к позитивному эффекту, каковы в этом плане возможности, компетенция и ответственность правотворческих субъектов и др., ответы на которые требуют комплексного научного решения, что позволит, среди прочего, конструктивно повлиять на существующую правотворческую практику.

На наш взгляд, одной из проблемных областей доктрины современного правотворчества является то, как этот вид особо значимой государственно-социальной деятельности вписывается в культурный фон общества, нации, государственно-правовой семьи, в какой мере он испытывает влияние подходов к созданию права из других политико-правовых систем, как проявляется суверенность национального правового творчества, а также то (что особенно важно), каким должно быть культурное наполнение собственно правотворческого процесса, какой должна быть культура организации правотворчества и на каком культурном уровне осуществляется правотворческий процесс, в частности, в современной России.

В целом следует отметить, что данная проблематика входит в более широкий круг вопросов правообразования - доктринальноправовой проблемы, позволяющей уяснить сущность, содержание позитивного права и вывести на понимание качества закона, от которого зависит состояние правозаконности и правопорядка в обществе. Как известно, изучение проблемы образования права помогает найти ответ на важный и, как правило, всегда актуальный вопрос: относится ли юридическая (правовая) норма к числу «изобретений», искусственных творений, создаваемых субъектами правотворчества, или же она результат более сложного объективного процесса, происходящего в глубинах социальноправовой жизни и выражающего факт ее возникновения и последующей динамики? Ответ 
на этот вопрос отрывает простор для последующих умозаключений и выводов, определяющих понимание сущности права и его роли в жизни общества, а также всех компонентов его материи (норм, юридических конструкций и пр.), их природы и законов существования в единой системе.

Правовая (юридическая) норма в большинстве случаев характеризуется как результат сознательной деятельности людей (законодателей, правотворцев), и это, пожалуй, уже стало элементарной истиной, не требующей каких-либо особых доказательств. Однако правовую норму не следует рассматривать исключительно как продукт их законодательной (правотворческой) активности, правотворческой воли. Правовая норма привносится в волевые рамки субъектов правотворчества извне под влиянием разнообразных факторов (социальных и пр.), которые существуют еще до того, как начинается процесс правотворчества, и продолжают влиять на него по мере осуществления. Эти прежде всего объективные факторы оказывают первоначальное воздействие на формирование права, находясь вне каждого отдельного правотворческого акта и предшествуя ему. Такое представление способствует более глубокому осмыслению особенностей процесса правообразования, а также создает предпосылки для ограждения правотворческой деятельности от вредного для нее субъективизма [13-15].

В то же время не следует понимать правообразовательный процесс только как объективный, не зависящий от разумной деятельности людей (народа и его представителей в лице законодательных и иных правотворческих органов). Иначе эти субъекты могли бы рассматриваться лишь как некие бесчувственные (неодушевленные и самостоятельно не мыслящие) машины, регистрирующие правовые импульсы, исходящие из «недр» социально-правовой жизни. Однако такое восприятие вряд ли уместно и целесообразно. Помимо своей ошибочности, оно существенно снижало бы авторитет государства как специально созданной людьми особой организации публичной власти, призванной упорядочивать различные социально-правовые процессы, регулировать общественные отношения, вносить в жизненные (подчас - стихийные) процессы элементы планомерности, предсказуемости и пр.

При моделировании картины правообразовательного процесса важно опираться на комплексный подход, который учитывает и естественно-социальное начало в правообразовании, и роль законодателя (в широком смысле этого слова) в создании необходимых обществу правовых норм. При этом последним, то есть законодателем, эти нормы должны формулироваться не произвольно (как вздумается правотворческому субъекту), а реально отражать социальные правообразующие факторы, складывающиеся на их основе социальные правовые интересы и соответствующие этим интересам правовые идеи, которые и будут находить свое закрепление в нормах правовых актов [18; 20; 21, с. 55-68; 22].

Исходя из этого, важно отметить необходимость соответствия законодательного (правотворческого) процесса базовым принципам и необходимым культурным требованиям с точки зрения организации данного юридического процесса и выполнения в ходе его осуществления стоящих перед ним общих и специальных, стратегических и тактических задач, ведь именно соблюдение этих искомых правокультурных критериев на этапе разработки и принятия нормативных правовых актов в последующем станет играть существенную роль в функциональности той или иной нормы права, тем самым минимизируя проблемы реализации введенных в действие нормативных предписаний на практике.

\section{Правовое творчество}

\section{как планомерно-сознательный способ создания права: основы теории предмета}

Способы создания права, которые были выработаны в ходе правовой эволюции, можно подразделить на два основных типа. Это деление производится в зависимости от того, является или же не является создание права результатом сознательной и планомерно осуществляемой деятельности. Процесс создания права, в котором сознательная и планомерная деятельность играет незначительную роль, называется спонтанным. В свою очередь создание права, при котором его творец 
сознает, что он создает право и действует более или менее планомерно, является сознательным $[11 ; 18 ; 25]$. В последнем случае речь идет собственно о правотворчестве, которое в условиях современного общества является преобладающим способом создания правовых норм.

Правотворчество как планомерно-сознательный способ правообразования - это сложный, требующий высокоточной организации интеллектуальный (рационально организованный) процесс актуального конструирования права как регулирующего средства. Этот процесс имеет свои особые характеристики, строится на определенных принципах, связан с реализацией общих и специальных функций и пр. Его отличие от правообразования спонтанного типа в том, что рациональное начало выходит в данном случае на передний план. Оперируя разумом, субъект правотворчества либо старается надлежащим образом понять и реально отобразить те модели правового поведения (взаимодействия), которые сложились объективным образом и их необходимо лишь правильно зафиксировать в нормах и текстах нормативных актов, либо принимает ответственные правовые решения, которые рассчитаны на моделирование неких новых, ранее не существовавших общественных отношений, появление которых, по мнению законодателя, целесообразно. В последнем случае проявляется наряду с рациональным подходом непосредственно творческое (конструкторское) начало. Законодатель в этом качестве выступает как своего рода «архитектор» права.

Правотворчество - рационализированный путь создания права - состоит в формировании и последующем формулировании, то есть возведении в закон (в широком смысле этого слова, включая каждый нормативно-правовой акт, рассчитанный на всеобщий характер применения) государственной воли компетентными на это субъектами. В отличие от санкционирования спонтанно сформированных обычно-правовых регуляторов, правотворчество характеризуется тем, что государство или с его согласия иные субъекты изначально выступают инициаторами создания и официального закрепления в системе источников права формально-определенных общеобязательных правил поведения.
Как планомерно-рациональный способ правообразования правотворческий процесс представляет собой систему производимых на объективной социальной основе организационно-процессуальных действий уполномоченных органов (главным образом, законодательных) государства, направленных на установление, изменение или отмену норм права. В качестве непосредственного результата правотворческой деятельности выступают различные правовые акты (нормативного характера). Главным правовым следствием правотворческой деятельности служит создание нормативной основы - совокупности действующих норм, являющихся исходным моментом в механизме правового регулирования и обеспечивающих правовое урегулирование общественных отношений либо составляющих возможность упорядочения общественных отношений, превращение которой в действительность связано с приведением в действие различных других способов реализации права (применение, использование, соблюдение, исполнение).

Приведем в качестве дополнительного опорного понятия правотворческого процесса определение такового, предлагаемое одним из ведущих специалистов в этой области И.В. Гранкиным: «Процесс разработки, обсуждения и принятия общеобязательных правил поведения людей (в форме правовых актов нормативного характера. - B. T., B. C.) компетентным органом государственной или муниципальной власти, подписания уполномоченным должностным лицом и последующее обнародование в официальном средстве массовой информации называется правотворчеством» [5, с. 38]. Было бы также верно дополнить, что несмотря на высокую роль субъективного начала в правотворчестве (зависимость его результатов от деятельности компетентных должностных (органов) лиц - субъектов правового творчества), само правотворчество - это все же социально обусловленный процесс, так как и содержание, и форма права детерминируются социальными правообразующими факторами, и только в таком понимании неразрывной связи действий законодателя и правообразующей воли, исходящей от общества, можно рассчитывать на перспективный успех всех тех творческих начинаний, которыми характеризует- 
ся планомерно-рациональный процесс правового созидания.

Правотворческий процесс основывается на определенных принципах - основополагающих идеях, реализация которых обеспечивает его качество и эффективность. Основными принципами правотворчества являются: 1) народный характер правотворчества; 2) демократизм правотворчества; 3 ) научный характер правотворчества и его связь с правоприменительной практикой; 4) законность правотворчества; 5) принцип системности и др. [15; 18]. Каждый из них выражает объективные условия, сопровождающие рациональную деятельность в области государственного (муниципального и иного социального) управления общественными процессами, и способствует надлежащей организации этой компетентной деятельности (в данном случае в сфере создания юридических стандартов социального взаимодействия).

Правотворческий процесс - это сложная деятельностная система, в результате динамики (функционирования) которой происходит конструирование (сотворение) позитивного права, выражаемого в определенных формах (в виде законов и иных нормативных актов, прецедентных решений судебной и административной власти, нормативных договоров, юридико-доктринальных положений и некоторых других) и нацеленного на решение тех или иных социальных (политических, экономических, социально-обеспечительных и пр.) задач.

Как было отмечено выше, в отличие от спонтанного правообразования правотворчество - это, как правило, рационально организованная деятельность компетентных властных инстанций, призванных управлять социальными процессами путем принятия соответствующих правовых актов (актов всеобщего действия), но вместе с тем напрямую зависящая от социального контекста. Данный аспект определяет специфику правотворческой деятельности (высокую роль разумного начала, особую целевую направленность и, помимо этого, с одной стороны, «социильно обусловленную» свободу законодателя в реализации своих правотворческих полномочий, а с другой бремя ответственности за качество принимаемых по воле субъектов правового творчества нормативных правовых актов).

\section{Правотворческие функции: к проблеме реализации}

Резонно констатировать: как и любая система, состоящая из тех или иных элементов, система правотворческой деятельности предполагает осуществление необходимых (обусловленных объективным предназначением правотворчества создавать позитивное право) функиий как общего характера (базовая функция правосозидания, в том числе официальная практика разработки и введения в действие новых норм права; внесение изменений в действующее законодательство или отмена каких-либо уже существующих государственно-обязательных правил поведения; восполнение пробелов в праве и пр.), так и специального характера (например, познавательная функция, аксиологическая функция и пр.), выполнение которых имеет значение для реализации основного функционального требования, заложенного в правотворческом процессе как таковом. Реализация этих функций позволяет решить задачу совершенствования современного законодательства.

Роль функционального подхода в понимании «механики» правотворческого процесса представляется крайне важной в прикладном аспекте, так как ненаделение деятельностной системы правотворческого процесса необходимым набором функций (общих и специальных, основных и вспомогательных, функций первого, второго и других по очередности порядков) создает почву для негативных проявлений в правотворческой практике, поскольку если не очевидно то, какие непосредственно направления работы должен (или может) осуществлять правотворец (выступая субъектом правотворческого процесса), то и предъявлять какие-либо возражения (претензии) на счет качества и эффективности результатов правотворческой деятельности вряд ли возможно, с чем, собственно, и приходится сталкиваться обществу в настоящее время, когда имеют место законодательная инфляция (не случайно столь безграничную активность к постоянным изменениям «правил игры», осуществляемым в рамках властного нормотворчества, иронически сравнивают с «принтером», печатающим (штампующим) все новые и новые нормативные акты, что 
зачастую не только не улучшает ситуацию в экономике (и других сферах), но и приводит к довольно ощутимым издержкам [8, с. 5], правотворческим ошибкам (дефектам) [16, с. 6774; 24, с. 89-96], порождает кризисные явления в праве в целом [3; 4, с. 43-54] и пр.). Как представляется, должным образом налаживая работу каждой из правотворческих функций, можно достичь качества эффективности для всей системы правотворчества.

Доктрина права постепенно проявляет к этой проблеме все более пристальное внимание [19, с. 622-630]. В современной юридической литературе под функциями правотворческого процесса понимаются обусловленные правообразующей волей, требующей выражения в позитивном праве, спецификой правотворческой работы направления профессиональной деятельности, осуществляемой в рамках системных параметров правотворческого процесса непосредственно субъектами правотворческой компетенции (прежде всего, депутатами законодательных (представительных) органов власти), а также привлекаемыми к участию иными лицами (специалистами в определенных научных областях, прежде всего, учеными-юристами), по познанию содержания искомой воли, оценке на предмет юридической значимости отдельных его компонентов, а также преобразованию в формально-определенные правовые установления, и которые в системе (посредством последовательной реализации соответствующих направлений правотворческой работы) позволяют достичь необходимый правотворческий результат в виде правовых актов нормативного характера, нацеленных на решение текущих проблем правового регулирования и на перспективу [1, с. 39-53; 23, с. 135].

\section{Необходимость предъявления} культурных требований

к правотворческому процессу как залог минимизации проблем реализации правотворческих функций

Для того чтобы искомые функции (функции правотворчества) реализовывались эффективно, сам юридический процесс правового созидания должен осуществляться на высоком культурном уровне и отвечать определен- ному набору культурных требований. Ведь реализация правотворческих функций во многом зависит от культуры правотворчества в целом, и недостаток культуры организации данного процесса либо проявления антикультуры могут служить причиной существенных проблем в достижении основных целей правового творчества и реализации его функций, а порой создавать дополнительные преграды в развитии политико-правовой системы, ведущие к еще большей коллизионности права, нарастанию массы дублирующих правовых норм, дефектности конструктивных формирований в праве и др.

Культура правотворчества, как нам представляется, - это обусловленная общим культурным фоном страны (государства), нациии (народа), сложившимися традицииями политики (искусства) государственноправовой деятельности, доминирующчими свойствами политико-правовой системы совокупность соичально-правовых, материально-организационных, процедурнопроиессуальных, технико-юридических, личностно-образовательных характеристик, мероприятий и требований, сопровождающих прочесс подготовки и принятия правотворческих решений и предъявляемых к таковому, определяющих уровень и качество осуществляемого в государстве правового творчества, конструктивную реализачию всех правотворческих функичий, способствуюших достижению единого запланированного правотворческого результата в виде правовых актов нормативного характера, содержаших нормативные правовые предписания, нормы права и согласованные юридические конструкичии с необходимым социально-правовым эффектом действия.

Культура правотворчества является залогом и формой реализации всех присущих этой деятельности задач. Д.А. Керимов, знаменитый теоретик права, не случайно назвал одну из своих работ именно в этом ключе: «Культура и техника законотворчества» [9]. Эта книга, вышедшая на этапе становления демократического устройства в России, обозначила одну из основных проблем правового творчества - проблему его культуры, актуальность и значимость которой только возра- 
стает на современном этапе и требует серьезного осмысления: ведь именно культура оглавляет название этой юридической работы, становясь как бы отправной точкой сложного и многогранного процесса правового творчества.

Каковы основные требования культуры правотворчества, которые могут и должны быть применимы на практике? Выделим, на наш взгляд, наиболее характерные:

1. Позиционируя правовое творчество как процесс социально обусловленный, в культурные параметры такового на первом плане должен входить комплекс действий субъектов правотворчества, осуществляемых на так называемой предправотворческой стадии. Это все то, что связано с выявлением именно тех отношений, которые требуют правового регулирования - базовая предпосылка выражения социальной природы права в «продуктах» правового творчества. «Необходимой предпосылкой создания правовых норм является познание тех сложных условий, факторов и обстоятельств, тех развивающихся общественных отношений, правовое регулирование которых диктуется нуждами социального прогресса» [10, с. 109].

2. Соответствие регламентным требованиям правотворческого проиесса. Одним из культурных требований правотворческого процесса является соблюдение основных регламентов этого процесса (от внесения проекта нормативно-правового акта на рассмотрение до его принятия в завершающем чтении). Например, применительно к общефедеральному законотворчеству один из основных документов подобного рода - это Постановление Государственной Думы Федерального Собрания Российской Федерации от 22 января 1998 г. № 2134-II ГД «О регламенте Государственной Думы Федерального Собрания Российской Федерации». В нем можно выделить некоторые статьи и пункты, которые наиболее ярко отражают культуру взаимодействия государства и общества, правовых экспертов в прочессе правотворчества. Например, п. «р» ст. 11 указывает на необходимость направления заключения Общественной Палаты Российской Федерации (далееОбщественная Палата) по результатам экспертизы законопроекта в комитет Государственной Думы, назначенный в соответствии с ч. 1 ст. 108 настоящего Регламента ответственным по указанному законопроекту. Пункт 2 ст. 27 гласит о том, что комитет, комиссия вправе привлекать к своей работе экспертов Правового управления Аппарата Государственной Думы и других экспертов, а также принимать решение о проведении независимой экспертизы законопроектов. Пункт 4 той же статьи определяет, что комитет Государственной Думы, назначенный в соответствии с ч. 1 ст. 108 настоящего Регламента ответственным по законопроекту, обязан рассматривать заключение Научного совета по правотворчеству по результатам экспертизы законопроекта, поступившее в соответствии с пунктом «3. 2» ч. 1 ст. 11 настоящего Регламента [17]. Информация о результатах рассмотрения комитетом указанного заключения доводится до сведения депутатов Государственной Думы РФ в выступлении представителя комитета при обсуждении законопроекта на заседании Государственной Думы. Это позволяет привлечь к работе экспертные группы и учесть их рекомендации при подготовке законопроекта.

Регламент содержит разнообразные требования к организации законотворческого процесса на федеральном уровне (процедурнопроцессуальные, юридико-технические, ориентированные на связь процесса правотворчества с социальным контекстом и пр.), выполнение которых символизирует во многом культуру осуществления законотворчества на общефедеральном уровне. Подобные регламенты, по общему правилу, приняты и действуют на региональном и муниципальном уровнях правотворчества, и там, где это действительно работает, общая картина представляется в основных чертах позитивной. В целом же соблюдение всех предписанных требований и процедур - организационная предпосылка качественных и обоснованных во всех отношениях принимаемых правотворческих решений.

3. Владение правилами и соблюдение всех требований юридической техники, реализация искусства юридической техники в полном своем смысле. «Являясь средством создания и совершенствования права, юридическая техника сопутствует ему на всех этапах развития и всегда отражает его национальные и исторические особенности» 
[6, с. 314]. Это означает применение в правотворческой практике всей совокупности методов, средств и приемов, используемых в соответствии с принятыми правилами при выработке и систематизации нормативно-правовых актов, что также является одним из определяющих культурных требований к правотворческому процессу, обеспечивающих создание наиболее совершенных юридических актов. «Техническое несовершенство представляет собою несовершенство всего права, недостаток, тормозящий право и вредящий ему во всех его целях и задачах» (Р. Иеринг) [23, с. 189].

4. Культура субъектов правотворческого прочесса. Невозможно отрицать личностное начало в правотворчестве, ведь в каждом его «продукте», к примеру, нормативноправовом акте, воплощаются мысли людей, прошедшие определенную процедуру, многочисленные фильтры, и воплощенные в строго фиксированной и установленной государством юридической форме. За созданным в процессе правотворчества нормативно-правовым актом так или иначе стоит автор (авторы), которые внесли в содержание законопроекта все его основные элементы (начиная от идеи и продолжая всеми аспектами правотворческой техники, способствующей построению содержания правового акта) [2, с. 11]. Поэтому культура лии, осуществляюших правотворческую деятельность, должна быть высока (в части образования, мировоззрения, знания права и юридического искусства и пр.). И если говорить в целом, заглядывая в будущее, необходимо констатировать, что «в обществе нужны технологии, развивающие массовое стремление к саморазвитию, социально-правовому и культурному самосовершенствованию, постоянному повышению профессионального уровня» [7, с. 121].

5. Иные культурные требования, связанные с отдельными стадиями и функциями правотворческого процесса в целом (аксиология в правотворчестве, познавательная функция, моделирование, этика правового творчества и пр.), соблюдение которых может способствовать оптимизации правотворческого процесса на всех уровнях [12] (генерируясь от локально-корпоративного уровня и восходя к уровню государства во всем его масштабе - федеральному правотворчеству).

\section{Выводы}

Учитывая культурные требования к правотворчеству, приведенные в данной работе, перечень которых может быть дополнен и детализирован, необходимо заметить, что правовое творчество - это процесс, который всегда находится в динамике, коммуникации с реальным изменяющимся обществом, ищет новые наиболее эффективные пути разрешения общественных проблем, улучшения и упорядочения жизни. Очевидно влияние культуры на правовое творчество, на круговую взаимосвязь этой сложной деятельности и социально-правовой коммуникации, обеспечивающей процесс познания правового содержания социальной жизни и его преобразования в правовые формы. Именно эта закономерная связь непосредственным образом и создает вращение «колеса» правового творчества в нужном направлении - к наибольшей гармонизации, упорядочиванию жизни людей.

Правотворчество призвано в первую очередь создавать право, делать право эффективным, реализуя свои основные и вспомогательные функции: правосозидания; принятия новых нормативных правовых актов, внесения изменений в действующее законодательство (обновление нормативного материала) или отмены каких-либо уже существующих нормативно-правовых актов; устранение коллизионности нормативных предписаний, восполнение пробелов в праве, правопознания, правового прогнозирования, моделирования и пр.

В минимизации проблем реализации правотворческих функций должно быть заинтересовано как государство, так и общество. В связи с этим необходимо учитывать контекст влияния культуры на право и правовое творчество, предъявляющий к этому сложному, многоэтапному процессу широкий ряд важных культурных требований (связь с социальным контекстом, соответствие регламентным требованиям, выполнение правил техники правотворчества и др.), направленных на повышение эффективности этого процесса и уровня социализации правотворческих результатов - нормального восприятия и функционирования в обществе его продуктов (норм права). Несомненным образом проблема реализации правотворческих функций за- 
висит от культуры организации данного юридического процесса, его соответствия правокультурным требованиям, начиная от способности выражения в правовом творчестве социальной природы права и заканчивая культурой непосредственно субъектов правотворческого процесса.

\section{ПРИМЕЧАНИЕ}

${ }^{1}$ Исследование выполнено при финансовой поддержке Российского фонда фундаментальных исследований (Отделение гуманитарных и общественных наук), проект № 15-03-00238 «Социальноинтерактивные закономерности права: проблемы методологии и теории».

\section{СПИСОК ЛИТЕРАТУРЫ}

1. Баранова, М. В. Теоретико-методологические аспекты исследования функций правотворческого процесса: постановка базовой проблемы функциональной характеристики опережающего законотворчества / М. В. Баранова // Вестник Саратовской государственной юридической академии. 2016. - № 5 (112). - С. 39-53.

2. Баранов, В. М. Личное в правотворчестве: утопия, антропологический ресурс или необходимое технико-юридическое средство повышения качества / В. М. Баранов, В. В. Трофимов // Юридическая наука и практика: Вестник Нижегородской академии МВД России. - 2015. - № 2 (30). - С. 9-18.

3. Власенко, Н. А. Избранное / Н. А. Власенко. - М. : Норма, 2015. -672 c.

4. Власенко, Н. А. Кризис права: проблемы и подходы к решению / Н. А. Власенко // Журнал российского права. - 2013. - № 8. - С. 43-54.

5. Гранкин, И. В. Правотворческий процесс / И. В. Гранкин. - М. : Проспект, 2016. - 192 с.

6. Давыдова, М. Л. Юридическая техника: проблемы теории и методологии / М. Л. Давыдова. - Волгоград : Изд-во ВолГУ, 2009. - 318 с.

7. Жинкин, С. А. Вопросы технологии правового воздействия на правовую культуру личности / С. А. Жинкин // Юридическая техника. - 2016. № 10. - С. 119-122.

8. Зубков, И. Выключите принтер / И. Зубков // Российская газета. - 2016. - № 114 (6982). - С. 5.

9. Керимов, Д. А. Культура и техника законотворчества / Д. А. Керимов. - М. : Юрид. лит., 1991. $160 \mathrm{c}$.

10. Керимов, Д. А. Методологический аспект правотворчества / Д. А. Керимов // Вопросы философии. - 1975. - № 5. - С. 108-119.
11. Лукич, Р. Методология права / Р. Лукич. М. : Прогресс, 1981. - 305 с.

12. Мартьянов, Г. А. Теория и методика оптимизации федерального законотворческого процесса / под ред. проф. С. А. Комарова. - СПб. : Изд-во Юрид. ин-та (Санкт-Петербург), 2010. - 180 с.

13. Научные основы советского правотворчества / под ред. Р. О. Халфиной. - М. : Наука, 1981. $317 \mathrm{c}$.

14. Нашиц, А. Правотворчество. Теория и законодательная техника / А. Нашиц. - М. : Прогресс, 1974. $-256 \mathrm{c}$.

15. Поленина, С. В. Законотворчество в Российской Федерации / С. В. Поленина. - М. : ИГП РАН, 1996. - $180 \mathrm{c}$.

16. Поленина, С. В. Правотворческие ошибки в свете факторного анализа законодательства // Правотворческие ошибки: понятие, виды, практика и техника устранения в постсоветских государствах: материалы Междунар. науч.-практ. круглого стола (2930 мая 2008 г.) / под ред. В. М. Баранова, И. М. Мацкевича. - М. : Проспект, 2009. - С. 67-74.

17. Постановление Государственной Думы Федерального Собрания Российской Федерации от 22 янв. 1998 г. № 2134-ІІ ГД : (ред. от 19 мая 2017 г.) «О Регламенте Государственной Думы Федерального Собрания Российской Федерации» // Собрание законодательства РФ. - 1998. - № 7. - Ст. 801.

18. Придворов, Н. А. Правообразование и правообразующие факторы в праве / Н. А. Придворов, В. В. Трофимов. - М. : Норма : ИНФРА-М, 2012.$400 \mathrm{c}$.

19. Реутов, В. П. Функции и структура правотворчества (стратегический аспект) / В. П. Реутов // Юридическая техника. -2015. - № 9. - С. 622-630.

20. Соколова, А. А. Социальные аспекты формирования права / А. А. Соколова. - Минск : ЕГУ, 2003. - $160 \mathrm{c}$.

21. Соколова, А. А. Социальные предпосылки формирования права / А. А. Соколова // Проблемы теории права и государства, истории политикоправовой мысли : сб. работ учеников, друзей, коллег профессора Олега Эрнестовича Лейста. - Алматы, 2005. - С. 55-68.

22. Трофимов, В. В. Правообразование в современном обществе: теоретико-методологический аспект / В. В. Трофимов ; под ред. д-ра юрид. наук, проф. Н. А. Придворова. - Саратов, 2009. - 308 с.

23. Трофимов, В. В. Социология права : словарьсправочник / отв. ред. В.В. Трофимов, А. В. Малько [и др.]. - Тамбов : Изд-во ТГУ им. Г. Р. Державина, 2016. $-282 \mathrm{c}$.

24. Херсонцев, А. И. Дефекты правотворчества и качество законодательных актов / А. И. Херсонцев // Российский юридический журнал. - 2007. № 1. - С. 89-96. 
25. Явич, Л. С. Сущность права: Социально-философское понимание генезиса, развития и функционирования юридической формы общественных отношений / Л. С. Явич. - Л. : Изд-во ЛГУ, 1985. -207 с.

\section{REFERENCES}

1. Baranova M.V. Teoretiko-metodologicheskie aspekty issledovaniya funktsiy pravotvorcheskogo protsessa: postanovka bazovoy problemy funktsionalnoy kharakteristiki operezhayushchego zakonotvorchestva [Theoretical and Methodological Aspects of Studying Law-Making Process's Functions: Formulation of Basic Problems of Functional Characteristics of Priority Legislation]. Vestnik Saratovskoy gosudarstvennoy yuridicheskoy akademii [Science Journal of Saratov State Juridical Academy], 2016, no. 5 (112), pp. 39-53.

2. Baranov V.M., Trofimov V.V. Lichnoe v pravotvorchestve: utopiya, antropologicheskiy resurs ili neobkhodimoe tekhniko-yuridicheskoe sredstvo povysheniya kachestva [Personal in Law: Utopia, Anthropological Resource or the Necessary Technical and Legal Means of Improving Quality]. Yuridicheskaya nauka i praktika: Vestnik Nizhegorodskoy akademii MVD Rossii [Juridical Science and Practice: Science Journal of Nizhny Novgorod Academy of Russian MIA], 2015, no. 2 (30), pp. 9-18.

3. Vlasenko N.A. Izbrannoe [Selected Works]. Moscow, Norma Publ., 2015. 672 p.

4. Vlasenko N.A. Krizis prava: problemy $\mathrm{i}$ podkhody k resheniyu [Crisis of Law: Problems and Approaches to Solving]. Zhurnal rossiyskogo prava [Journal of Russian Law], 2013, no. 8, pp. 43-54.

5. Grankin I.V. Pravotvorcheskiy protsess: ucheb. posobie [Law-Making Process]. Moscow, Prospekt Publ., 2016. 192 p.

6. Davydova M.L. Yuridicheskaya tekhnika: problemy teorii i metodologii: monografiya [Juridical Technique: Problems of Theory and Methodology: Monograph]. Volgograd, Izd-vo VolGU, 2009. 318 p.

7. Zhinkin S.A. Voprosy tekhnologii pravovogo vozdeystviya na pravovuyu kul'turu lichnosti [Problems of Technology of Legal Impact on the Legal Culture of the Personality]. Yuridicheskaya tekhnika, 2016, no. 10, pp. 119-122.

8. Zubkov I. Vyklyuchite printer [Turn the Printer off]. Rossiyskaya gazeta, 2016, May 27, no. 114 (6982), p. 5.

9. Kerimov D.A. Kultura i tekhnika zakonotvorchestva [Culture and Technique of LawMaking]. Moscow, Yurid. lit., 1991. 160 p.

10. Kerimov D.A. Metodologicheskiy aspekt pravotvorchestva [Methodological Aspect of Law Creation]. Voprosy filosofii, 1975, no. 5, pp. 108-119.
11. Lukich R. Metodologiya prava [Methodology of Law]. Moscow, Progress Publ., 1981. 305 p.

12. Martyanov G.A. Teoriya $i$ metodika optimizatsii federalnogo zakonotvorcheskogo protsessa: monografiya [Theory and Methods of Optimization of the Federal Law-Making Process. Monograph]. Saint Petersburg, Izd-vo SPb Yurid. in-ta, 2010. 180 p.

13. Khalfina P.O., ed. Nauchnye osnovy sovetskogo pravotvorchestva [The Scientific Basis of the Soviet Law-Making]. Moscow, Nauka Publ., 1981. $317 \mathrm{p}$.

14. Nashits A. Pravotvorchestvo. Teoriya $i$ zakonodatelnaya tekhnika [The Law-Making. Theory and Legislative Technique]. Moscow Progress, 1974. $256 \mathrm{p}$.

15. Polenina S.V. Zakonotvorchestvo $v$ Rossiyskoy Federatsii [Law-Making in the Russian Federation]. Moscow, IGP RAN Publ., 1996. 180 p.

16. Polenina S.V. Pravotvorcheskie oshibki v svete faktornogo analiza zakonodatelstva [Law-Making Mistakes in the Light of the Factor Analysis of the Legislation]. Baranov V.M., Matskevich I.I., eds. Pravotvorcheskie oshibki: ponyatie, vidy, praktika $i$ tekhnika ustraneniya $v$ postsovetskikh gosudarstvakh: materialy Mezhdunar. nauch.-prakt. kruglogo stola (29-30 maya 2008 g.) [Legislative Mistakes: Definition, Types, Practice and Technique of Elimination in the Post-Soviet Countries: Proceedings of International Scientific-Practical Round Table (29-30th of May, 2008)]. Moscow, Prospekt Publ., 2009, pp. 67-74.

17. Postanovlenie Gosudarstvennoy Dumy Federalnogo Sobraniya Rossiyskoy Federatsii «O Reglamente Gosudarstvennoy Dumy Federalnogo Sobraniya Rossiyskoy Federatsii» ot 22 yanv. 1998 g. № 2134-II GD (red. ot 19 maya 2017 g.) [The Resolution of the State Duma of the Federal Assembly of the Russian Federation "On Regulation of State Duma of the Federal Assembly of the Russian Federation" of January 22, 1998 no. 2134-II GD (amend. of May 19, 2017)]. Sobranie zakonodatelstva Rossiyskoy Federatsii [Collected Legislation of the Russian Federation], 1998, no. 7, art. 801.

18. Pridvorov N.A., Trofimov V.V. Pravoobrazovanie i pravoobrazuyushchie faktory $v$ prave: monografiya [Law-Making and Law-Making Factors in Law: Monograph]. Moscow, Norma Publ.; INFRA-M Publ., 2012. 400 p.

19. Reutov V.P. Funktsii i struktura pravotvorchestva (strategicheskiy aspekt) [Functions and Structure of the Law-Making (Strategic Aspect)]. Yuridicheskaya tekhnika, 2015, no. 9, pp. 622-630.

20. Sokolova A.A. Sotsialnye aspekty formirovaniya prava [Social Aspects of Law Formation]. Minsk, EGU Publ., 2003. 160 p. 
21. Sokolova A.A. Sotsialnye predposylki formirovaniya prava [Social Preconditions of Law Formation]. Problemy teorii prava i gosudarstva, istorii politiko-pravovoy mysli. Sbornik rabot uchenikov, druzey, kolleg professora Olega Ernestovicha Leysta [Problems of Theory of State and Law, History of Political and Legal Thought. The Collection of Works of Students, Friends and Colleagues of Professor Oleg Ernestovich Leist]. Almaty, 2005, pp. 55-68.

22. Trofimov V.V. Pravoobrazovanie v sovremennom obshchestve: teoretiko-metodologicheskiy aspekt [The Law-Making in the Modern Society: Theoretical and Methodological Aspect]. Saratov, 2009. 308 p.

23. Trofimov V.V., Malko A.V., et al. Sotsiologiya prava: slovar-spravochnik [Sociology of Law: Dictionary-
Handbook]. Tambov, TGU im. G. R. Derzhavina Press, 2016. 282 p.

24. Khersontsev A.I. Defekty pravotvorchestva i kachestvo zakonodatelnykh aktov [Defects of LawMaking and Quality of Legislative Acts]. Rossiyskiy yuridicheskiy zhurnal [Russian Juridical Journal], 2007, no. 1, pp. 89-96.

25. Yavich L.S. Sushchnost prava: Sotsialnofilosofskoe ponimanie genezisa, razvitiya $i$ funktsionirovaniya yuridicheskoy formy obshchestvennykh otnosheniy [Essence of Law: a Social-Philosophical Understanding of Genesis, Development and Functioning of the Legal Form of the Public Relations.]. Leningrad, LGU Press, 1985. 207 p.

\section{Information about the Authors}

Vasily V. Trofimov, Doctor of Juridical Sciences, Associate Professor, Professor of Department of the Theory and History of State and Law, Director of Research Institute for State Legal Studies, Derzhavin Tambov State University, Internatsionalnaya St., 33, 392000 Tambov, Russian Federation, iptgutv@mail.ru.

Vladimir Yu. Samorodov, Doctoral candidate, the Department of the Theory and History of State and Law, Derzhavin Tambov State University, Internatsionalnaya St., 33, 392000 Tambov, Russian Federation, vova.samorodov@yandex.ru.

\section{Информация об авторах}

Василий Владиславович Трофимов, доктор юридических наук, доцент, профессор кафедры теории и истории государства и права, директор Научно-исследовательского института Государственно-правовых исследований, Тамбовский государственный университет им. Г.Р. Державина, ул. Интернациональная, 33, 392000 г. Тамбов, Российская Федерация, iptgutv@mail.ru.

Владимир Юрьевич Самородов, аспирант кафедры теории и истории государства и права, Тамбовский государственный университет им. Г.Р. Державина, ул. Интернациональная, 33, 392000 г. Тамбов, Российская Федерация, vova.samorodov@yandex.ru. 